\title{
Effects of Concept Mapping and Problem Solving Instructional Strategies on Secondary School Learning Outcomes in Chemistry
}

Abayomi Olajengbesi \& Dr. Kehinde Olugbenga Aluko

\section{Abstract}

The aim of the study was to determine the effect of concept mapping and problem solving instructional strategies on secondary school students' learning outcomes in Chemistry. The study adopted pre-test, post-test, control group quasiexperimental design, using a $3 \times 2 \times 2$ factorial matrix. Two null hypotheses were tested at 0.05 level of significance. The subjects consisted of two hundred and fifty (250) students, randomly selected from six secondary schools in Ibadan North Local Government Area of Oyo State, Nigeria. The subjects comprised of 148 males and 102 females. The instruments used to collect data were: "Chemistry Achievement Test (CAT)" r=0.756, "Chemistry Attitude Questionnaire (CAQ)" $r=0.756$, The data collected were analysed using inferential statistics of Analysis of Covariance (ANCOVA), and Scheffe post hoc analysis. The results showed that students exposed to problem solving instructional strategy had the highest mean score of 11.920 followed by those of concept mapping instructional strategy with mean score of 10.690 while those of conventional strategy obtained 7.290. There was a significant main effect of treatment on students' academic achievement in Chemistry $[F(1,237)=120.372 ; P<0.05]$ and also a significant main effect of treatment on students' attitude to Chemistry $[F(1,237)=16.387 ; P<0.05]$. Based on these findings, it was recommended that Problem Solving and Concept Mapping 
Instructional strategies should be adopted by teachers of Chemistry in teaching the subject.

\section{Introduction}

Science, according to Abdullahi (1982), has been described as the foundation upon which the bulk of the present technological breakthrough is built. The three basic sciences are Biology, Chemistry and Physics, but Chemistry stands in a central position among the basic sciences. The contribution of Chemistry in the provision of our basic needs, in improving the quality of our life, in the provision of knowledge about our environment, in serving as a requirement (pre-requisites) for admission into tertiary institutions for science, engineering and technology based courses, have all given the subject the unavoidable prominence it enjoys among the other school subjects. It is against this background that the nation should develop her Chemistry programme on a sound footing. One of the ways of doing this is to design strategies which can be used to improve the teaching and learning of Chemistry to make it more attractive to students.

In spite of the importance of Chemistry to the improvement of life and technology, students often show negative attitude to the subject and this is associated with poor performance (Odunsi, 1984; Ojo, 1990).

Federal and State Governments have embarked on a number of measures to attract and encourage students to study science. The measures include, establishment of Basic and Remedial science colleges to enable students meet university entry requirements in science related courses 
(Udoh, 1998), provision of adequate facilities, provision of automatic employment to science teachers and payment of science allowance to science teachers among others. But these do not seem to yield positive results as Chemistry students continue to perform poorly (Udoh, 1998).

A number of studies have been carried out in an attempt to investigate the causes of poor performance in Chemistry. Some of the causes identified include:

(i). difficulty in recalling, representing or writing ionic equations (Ahiakwo, 1984; Onwu and Moneme, 1986)

(ii). problem of language of instruction (Ajeyalemi and Busari, 1986)

(iii). lack of organizational skill in solving quantitative problems (Onwu, 1982, Onwu and Moneme 1986; Adesoji, 1991)

(iv). use of expository method by teachers while teaching almost all aspects of science (Ogunniyi, 1986).

The investigator therefore contends that if teaching strategies such as concept mapping and problem solving are used to teach Chemistry, learners are likely to be better improved in terms of conceptual thinking, intuitive knowledge and insightful learning. Such learners are also likely to display an improved level of achievement.

\section{Purpose of the study}

This study intended to determine the effects of concept mapping and problem solving strategies on senior secondary school students' learning outcomes in Chemistry.

\section{Hypotheses}

The following null hypotheses were tested at 0.05 level of significance: 
$\mathrm{H}_{0} 1$ : There is no significant main effect of treatment on students' achievement in Chemistry

$\mathrm{H}_{0}$ 2: There is no significant main effect of treatment on students' attitude towards Chemistry

\section{Definition of Terms}

Concept mapping: It is an instructional strategy that involves graphical or diagrammatical representation of concepts achieved by selecting and arranging concepts from lessons into meaningful hierarchy, showing relationship between levels and among concepts.

Problem Solving: This is a cognitive learning strategy which has to do with bridging the gap between the problem state and the solution state.

Learning Outcomes: These are the scores derived from achievement test and attitude questionnaire.

Attitude: This refers to the students' disposition or feeling towards a concept.

\section{Research Methodology}

\section{Research Design}

This study employed pre-test, post-test, control group quasi-experimental design, using a $3 \times 2 \times 2$ factorial matrix. The design has treatment at three levels crossed with cognitive style at two levels and gender at two levels.

\section{Sample and Sampling Technique}

The study population was all the Senior Secondary two Chemistry students in Ibadan North Local Government Area of Oyo State, Nigeria. Purposive sampling was used to select six 
Effects of Concept Mapping and Problem Solving in Chemistry

schools. These schools were randomly assigned to the two experimental and control groups. From the selected schools, two intact Senior Secondary Two (SS II) Chemistry students' classes who were categorized either as analytical or nonanalytical were randomly selected to form the subjects for the study. The subjects comprised 250 Chemistry students made up of 148 males and 102 females.

SS II students were considered appropriate because these students were yet to treat the topics.

\section{Research Instruments}

The following instruments were used to collect data for the study:

Chemistry Achievement Test (CAT)

Chemistry Attitude Questionnaire (CAQ)

\section{Validity and Reliability of CAT}

Chemistry Achievement Test was given to four experienced Chemistry teachers for face and content validity.

A pilot study was carried out by giving the instrument to SS II Chemistry students in a representative school not meant for the research; Mufu Lanihun Comprehensive High School, Ibadan in Ibadan North East Local Government Area, Oyo State, Nigeria. This was done to enable the researcher remove the most simple and most difficult items. Thereafter, their responses were collated.

The same group of students was retested after two weeks. Kuder Richardson estimation of internal consistency of the items was found to be 0.756 while the test, retest reliability yielded a coefficient of stability of 0.7764 after correlating the scores on two administrations with a two weeks interval between tests. 


\section{Validity and Reliability of CAQ}

The instrument was given to four experienced Chemistry teachers to obtain their views in respect of the language level, the appropriateness and overall face validity of the instrument. The instrument was administered to SS II Chemistry students of Mufu Lanihun Comprehensive High School in Ibadan North East Local Government Area, Oyo State, Nigeria who were not part of the main study. Alpha Cronbach coefficient of 0.7561 was obtained from the validation carried out on the instrument.

\section{Data Analysis}

The data collected were analysed using the inferential statistics of Analysis of Covariance (ANCOVA), which was expected to correct for any initial differences in the dependent variables and other extraneous factors that could interfere with the treatment effects.

Multiple Classification Analysis (MCA) was used to show the magnitude and direction of the difference in performance of students in the various groups while Scheffe Post Hoc test was used to trace the source of significant main effects where they were detected.

\section{Results and Discussion}

Analysis of data and results were presented as they relate to the hypotheses.

Hypothesis 1: There is no significant main effect of treatment on students' achievement in Chemistry

In order to test this hypothesis, the data collected were analysed using Analysis of Covariance (ANCOVA) and Multiple 
Effects of Concept Mapping and Problem Solving in Chemistry

Classification Analysis (MCA). The summary of the findings are presented below.

\section{Table 1: Summary of $3 \times 2 \times 2$ ANCOVA of the Post-Test Achievement scores of subjects According to Treatment, Cognitive Style and Gender in Chemistry Achievement}

\begin{tabular}{|l|l|l|l|l|l|}
\hline Sources of Variance & $\begin{array}{l}\text { Sum of } \\
\text { Square }\end{array}$ & DF & $\begin{array}{l}\text { Mean } \\
\text { Square }\end{array}$ & F & $\begin{array}{l}\text { Sign } \\
\text { of F }\end{array}$ \\
\hline Covariates (Pre-Test) & 505.144 & 1 & 505.144 & 228.714 & .000 \\
\hline Main Effects & 1090.921 & 4 & 272.730 & 123.484 & $.00 *^{*}$ \\
\hline Treatment & 531.716 & 2 & 265.858 & 120.372 & \\
\hline Cognitive Style & 390.244 & 1 & 390.244 & 176.690 & $.000^{*}$ \\
\hline Gender & 49.687 & 1 & 49.687 & 22.497 & $.000^{*}$ \\
\hline 2-Way Interactions & 94.569 & 5 & 18.914 & 8.564 & $.000^{*}$ \\
\hline Treatment $\times$ Cognitive Style & 28.931 & 2 & 14.465 & 6.550 & $.002^{*}$ \\
\hline Treatment $\times$ Gender & 51.640 & 2 & 25.820 & 11.690 & $.000^{*}$ \\
\hline Cognitive Style $\times$ Gender & 21.105 & 1 & 21.105 & 9.556 & $.002^{*}$ \\
\hline $\begin{array}{l}\text { 3-Way Interactions } \\
\text { Sreatment } \times \text { Cognitive }\end{array}$ & 8.821 & 2 & 4.410 & 1.997 & .138 \\
\hline Explained $\times$ Gender & 1699.454 & 12 & 141.621 & 64.122 & .000 \\
\hline Residual & 526.446 & 237 & 2.209 & & \\
\hline TOTAL & 2222.90 & 249 & 8.927 & & \\
\hline
\end{tabular}

*Significant at $\mathrm{P}<0.05$

The summary of ANCOVA as contained in the Table 1 shows that there was a significant main effect of treatment on students' Chemistry achievement $[\mathrm{F}(1,237)=120.372 ; \mathrm{P}<$ 0.05]. This means that there is a significant difference in the post-test scores of subjects exposed to the concept mapping, problem solving and conventional method of instruction. 
In order to determine how each of the groups performed, a Multiple Classification Analysis (MCA) of the ANCOVA for Chemistry Achievement scores was carried out and the summary is presented in Table 2.

\section{Table 2 : Multiple Classification Analysis (MCA) of the Post-Test Achievement Scores of Subjects According to Treatment, Cognitive Style and Gender}

Grand Mean $=10.180$

\begin{tabular}{|l|l|l|l|l|l|}
\hline \multirow{2}{*}{ Variable + Category } & \multicolumn{2}{|l|}{$\mathbf{N}^{\prime}$} & \multicolumn{2}{|l|}{$\begin{array}{l}\text { Adjusted for } \\
\text { independents' + } \\
\text { Covariates }\end{array}$} \\
\cline { 2 - 6 } & & $\begin{array}{l}\text { Deviatio } \\
\mathbf{n}\end{array}$ & ETA & Deviation & BETA \\
\hline $\begin{array}{l}\text { Treatment } \\
\text { Concept Mapping }\end{array}$ & 90 & .51 & & .73 & \\
\hline Problem Solving & 90 & 1.74 & & 1.12 & \\
\hline Conventional & 70 & -2.89 & .63 & -2.39 & .50 \\
\hline $\begin{array}{l}\text { Cognitive Style } \\
\text { Analytical }\end{array}$ & 155 & 1.46 & & 1.07 & \\
\hline Non-analytical & 95 & -2.38 & .62 & -1.75 & .46 \\
\hline $\begin{array}{l}\text { Gender } \\
\text { Male }\end{array}$ & 148 & -.25 & & -.37 & .718 \\
\hline Female & 102 & .36 & .10 & .54 & .847 \\
\hline $\begin{array}{l}\text { Multiple R Squared } \\
\text { Multiple R }\end{array}$ & & & & & .75 \\
\hline
\end{tabular}

Note: Adjusted Post-Test Mean Score = Grand Mean + Adjusted Independent + Covariates for each category. 
The Multiple Classification Analysis table reveals that subjects in the Problem Solving Treatment Group had the highest Adjusted Post-Test Mean Score in Chemistry Achievement Test, 11.920. Subjects exposed to the Concept Mapping Treatment came second with an adjusted Post-test mean score of 10.690 while the control or conventional group obtained the least adjusted post-test mean score of 7.290. These adjusted post-test mean scores were obtained by adding the Grand Mean (10.180) with the respective adjusted deviations.

In order to determine the actual source of the significant main effect of the treatment as indicated in Table 2, Scheffe Multiple Range Test was employed as a post-hoc measure. The result of this test is shown below in Table 3.

Table 3: Summary of Scheffe Post-Hoc Analysis of Post-Test Mean Achievement of Subject According to Treatment Groups

\begin{tabular}{|l|l|l|l|l|}
\hline \multirow{2}{*}{ Treatment } & Mean Score & \multicolumn{3}{|l|}{ Treatment Group } \\
\cline { 3 - 5 } & & $\mathbf{1}$ & $\mathbf{2}$ & $\mathbf{3}$ \\
\hline Concept Mapping & 10.690 & & & $*$ \\
\hline 2. Problem Solving & 11.920 & $*$ & & $*$ \\
\hline 3. Control & 7.290 & & & \\
\hline
\end{tabular}

Note: * Denotes pairs of groups significantly different at the 0.05 level.

Table 3 shows that the Chemistry achievement scores of problem solving treatment group differs significantly from achievement scores in control group (conventional method).

Also concept mapping treatment group differs significantly from achievement scores in the control group. This implies that the significant effect of treatment obtained in Table 1 is as a result of the significant difference between the pairs of groups 1 and 3 as well as groups 2 and 3 . 
On the basis of these findings hypothesis 1 , which states that there is no significant main effect of treatment on students' Chemistry achievement is rejected.

\section{Hypothesis 2: There is no significant main effect of treatment on students' attitude towards Chemistry}

In order to test this hypothesis, the data collected were analysed using Analysis of Covariance (ANCOVA), Multiple Classification Analysis (MCA) and Scheffe Multiple range test to determine the source of significant difference if any. The summary of results is presented in Table 4.

Table 4: Summary of $3 \times 2 \times 2$ ANCOVA of the Post-Test Attitude Scores of Subjects According to Treatment, Cognitive Style and Gender on Attitude towards Chemistry

\begin{tabular}{|l|l|l|l|l|l|}
\hline Sources of Variance & $\begin{array}{l}\text { Sum of } \\
\text { Square }\end{array}$ & DF & $\begin{array}{l}\text { Mean } \\
\text { Square }\end{array}$ & $\mathbf{F}$ & $\begin{array}{l}\text { Sign of } \\
\text { F }\end{array}$ \\
\hline Covariates (Pre-Test) & 1816.700 & 1 & 1816.700 & 46.898 & .000 \\
\hline Main Effects & 1502.581 & 4 & 375.645 & 9.697 & $.000^{*}$ \\
\hline Treatment & 1269.603 & 2 & 634.801 & 16.387 & $.000 *$ \\
\hline Cognitive Style & 60.681 & 1 & 60.681 & 1.566 & .212 \\
\hline Gender & 53.002 & 1 & 53.002 & 1.368 & .243 \\
\hline 2-Way Interactions & 258.640 & 5 & 51.728 & 1.335 & .250 \\
\hline $\begin{array}{l}\text { Treatment } \times \text { Cognitive } \\
\text { Style }\end{array}$ & 26.839 & 2 & 13.419 & .346 & .708 \\
\hline Treatment $\times$ Gender & 165.874 & 2 & 82.937 & 2.141 & .120 \\
\hline Cognitive Style $\times$ Gender & 59.165 & 1 & 59.165 & 1.527 & .218 \\
\hline $\begin{array}{l}\text { 3-Way Interactions } \\
\text { Treatment } \times \text { Cognitive }\end{array}$ & 12.403 & 2 & 6.201 & .160 & .852 \\
\hline
\end{tabular}


Effects of Concept Mapping and Problem Solving in Chemistry

\begin{tabular}{|l|l|l|l|l|l|}
\hline Style $\times$ Gender & & & & & \\
\hline Explained & 3590.323 & & 299.194 & 7.724 & $.000^{*}$ \\
\hline Residual & 9180.733 & & 38.737 & & \\
\hline TOTAL & 12771.056 & & 51.289 & & \\
\hline
\end{tabular}

*Significant at $\mathrm{P}<0.05$

The summary of ANCOVA as contained in the Table shows that there was a significant main effect of treatment on students' attitude towards Chemistry $[F(1,237)=16.387$; $P<$ 0.05]. This means that there is a significant difference in the post-test scores of subjects exposed to the concept mapping, problem solving and conventional strategies.

In order to determine how each of the groups performed, a Multiple Classification Analysis (MCA) of the ANCOVA for attitude scores was calculated and the summary is presented in Table 5.

Table 5: Multiple Classification Analysis (MCA) of the Post-Test Attitude Scores of Subjects According to Treatment, Cognitive Style and Gender

Grand Mean $=62.576$

\begin{tabular}{|c|c|c|c|c|c|}
\hline \multirow[t]{2}{*}{ Variable + Category } & \multirow[t]{2}{*}{ 'N' } & \multicolumn{2}{|l|}{ Unadjusted } & \multicolumn{2}{|c|}{$\begin{array}{l}\text { Adjusted for } \\
\text { independents' + } \\
\text { Covariates }\end{array}$} \\
\hline & & Deviation & ETA & Deviation & BETA \\
\hline $\begin{array}{l}\text { Treatment } \\
\text { (1) Concept Mapping }\end{array}$ & 90 & 1.82 & & 1.39 & \\
\hline (2) Problem Solving & 90 & 1.57 & & 1.50 & \\
\hline (3) Conventional & 70 & -4.36 & .38 & -3.72 & .33 \\
\hline $\begin{array}{l}\text { Cognitive Style } \\
\text { (1) Analytical }\end{array}$ & 155 & .75 & & .39 & \\
\hline (2) Non-analytical & 95 & -1.22 & .13 & -.64 & .07 \\
\hline Gender (1) Male & 148 & -.40 & & -3.9 & \\
\hline
\end{tabular}




\begin{tabular}{|l|l|l|l|l|l|}
\hline & & & & & \\
\hline (2) Female & 102 & .58 & .07 & .56 & .07 \\
\hline Multiple R Squared & & & & & .260 \\
\hline Multiple R & & & & & .510 \\
\hline
\end{tabular}

Note: Adjusted Post-Test Mean Score $=$ Grand Mean + Adjusted Independent + Covariates for each category.

The Multiple Classification Analysis table reveals that subjects in the Concept Mapping Treatment Group had the highest Adjusted Mean Attitude Score of 64.4000 , followed by the subjects in the Problem Solving Treatment Group of 64.144 while the conventional (Control) Group obtained the lowest Post-Test Mean Score of 58.2143.

To determine the actual source of the significant main effect of the treatment on students' attitude towards Chemistry as indicated in Table 5, Scheffe Multiple Range Test was employed as a post-hoc measure. The result is shown in Table 6.

Table 6: Summary of Scheffe Post-Hoc Analysis of Post-Test Attitude Mean Scores of Students towards Chemistry According to Treatment Groups

\begin{tabular}{|l|l|l|l|l|}
\hline \multirow{2}{*}{ Treatment } & Mean & \multicolumn{3}{|l|}{ Treatment Group } \\
\cline { 3 - 5 } & Score & $\mathbf{1}$ & $\mathbf{2}$ & $\mathbf{3}$ \\
\hline 1 Concept Mapping & 64.4000 & & & $*$ \\
\hline 2. Problem Solving & 64.1444 & & & $*$ \\
\hline 3. Control & 58.2143 & & & \\
\hline
\end{tabular}

Note: *Denotes pairs of groups significantly different at the 0.05 level. 
Table 6 shows that Concept Mapping Treatment Group differs significantly from those of Problem Solving Treatment Group and the Control Group in their attitude means scores of $64.4000,64.1444$, and 58.2143 respectively.

Also Problem Solving Treatment Group differs significantly from Control Group. This implies that the significant effect of treatment obtained in Table 4 is as a result of the significant difference between the pairs of groups 1 and 3 as well as groups 2 and 3.

On the basis of these findings, hypothesis 2 , which states that there is no significant main effect of treatment on students' attitude towards Chemistry, is hereby rejected.

\section{Conclusion}

The results of the study implied that, the use of Problem Solving and Concept Mapping Instructional strategies in the teaching of Chemistry will help the students learn Chemistry more meaningfully than the use of conventional strategy. This is because the strategies are capable of making students more involved in their own learning, thereby improving their achievement and attitude towards Chemistry.

\section{Recommendations}

It is hereby recommended that Problem Solving and Concept Mapping Instructional strategies should be adopted by teachers of Chemistry in teaching the subject. In the use of these strategies, teachers should play the role of facilitators since problem solving and concept mapping instructional strategies are student-centred. Curriculum developers should organize forum for workshops on problem solving and concept mapping strategies particularly in Chemistry education so that the strategies can be adequately adopted by the teachers. The teachers should also be encouraged by paying their salaries and entitlements promptly. 


\section{References}

Abdullahi, A. (1982). Science Teaching in Nigeria. Ilorin: Atoto Press Limited.

Adesoji, F. A. (1997). Average Students and Effectiveness of Problem-Solving Instructional Strategies. Ife Journal of Educational Studies 4(1), 16-19.

Ahiakwo, M. J. (1982). Topic difficulties in Chemistry.

Unpublished M.Ed Dissertation, University of Ibadan, Ibadan.

Ahiakwo, M. J. (1988). Cognitive Style and Students' Problem Solving Behaviour in Chemistry. Unpublished Ph.D, Thesis University of Ibadan, Ibadan.

Ajeyalemi, D. (1983). The Teaching of Chemistry, An

Experience in Nigeria Secondary Schools, Problem and Prospects. Journal of the Science Teacher Association of Nigeria, 78, 72-85.

Odunsi, T. D. (1984). A Study of the Attitude of Some Nigerian Students towards Science Journal of Research in Curriculum 3(1) 3-17.

Ojo, M. O (1990). The differential effectiveness of cooperative, competitive and individualistic goal structures on students' performance in Nigeria. Unpublished Ph.D 
Effects of Concept Mapping and Problem Solving in Chemistry

Thesis, University of Ibadan, Nigeria.

Onwu, G. O (1982). Practical Teaching in Higher Education:

Chemistry. Adebar Publisher Ltd, Nigeria

Onwu, G. D. and Moneme, C. D. (1986). A Network of Student

Problem Solving Difficulties in Electrolysis, Journal of the Science Teacher Association of Nigeria 25(1), 103-114.

Udoh, O. A. (1998). Learning Environment Variables as

Correlates of Chemistry Students' Learning Outcomes in Akwa Ibom State Secondary Schools. Unpublished Ph.D Thesis University of Ibadan, Ibadan. 